\title{
Sex selection: sorting sperm as a gateway to the sorting society?
}

Edgar Dahl

Since ancient times, couples have been trying to influence the sex of their children. Following a suggestion by Aristotle, they were making love in the north wind to ensure the birth of a son and in the south wind to ensure the birth of a daughter. According to a proposal made by Galen, men were tying a string around their left testicle to make a boy and tying the right one to make a girl. In medieval times the proposed formula got even more bizarre when alchemists recommended to drink the blood of a lion and then have intercourse under a full moon to sire a son. ${ }^{1}$

Choosing the sex of our children is no longer a fantasy. However, the prospect of a reliable method for sex selection has not only raised old hopes, but also new fears. Many people are concerned that it may lead to an imbalance of the sexes, most likely a preponderance of males. Such an overabundance of men and a shortage of women, some sociologists have predicted, will invariably cause an enormous rise in enforced celibacy, polyandry, homosexuality, prostitution, rape and other sexual crimes. ${ }^{2}$ Many feminists are similarly alarmed. Some have called the deliberate choice of a male child 'the original sexist $\sin ^{3}{ }^{3}$ Others went so far as to warn us of an impending 'gynocide'. ${ }^{4}$ Are these fears justified? How well are they supported by empirical evidence? And most of all: does sex selection call for a legal ban?

Before turning to these questions, let us briefly review the state of the art. Currently, there are three different types of sex selection: sex-selective abortion, sex-selective embryo transfer and sex-selective insemination. Sex-selective abortion has been made possible by prenatal diagnosis. Amniocentesis, chorionic villus sampling and ultrasound not only allow for the detection of fetal abnormalities, but also for the determination of fetal sex. In principle, women may use the information to decide whether or not to terminate a pregnancy if the fetus is not of the desired sex. Using prenatal diagnosis for the

The Sorting Society: The Ethics of Genetic Screening and Therapy, ed. Loane Skene and Janna Thompson. Published by Cambridge University Press. (c) Cambridge University Press 2008. 
sole purpose of sex-selective abortions is, however, very rare in Western societies. For example, a follow-up study of 578 patients having prenatal diagnosis at one Melbourne centre found that none of the women had a termination for fetal sex. ${ }^{5}$ Going through the traumatizing experience of an abortion is usually seen as too high a price for a child of a particular sex.

Sex-selective embryo transfer has been facilitated by the arrival of pre-implantation genetic diagnosis, ${ }^{6}$ which is an alternative to prenatal diagnosis. It offers couples who are at risk of transmitting a genetic defect and are having in-vitro fertilization, the opportunity to have their embryos screened before they are transferred into the uterus. Since only those embryos that are free of the abnormality concerned will qualify for transfer to the womb, pre-implantation genetic diagnosis reduces the risk of bearing a child with a genetic disease and helps to avoid the difficult decision whether or not to terminate a pregnancy. Like prenatal diagnosis, preimplantation genetic diagnosis can also be used to determine the sex of the embryos. Thus, women may request to transfer only those embryos that are of the desired sex.

Sex-selective insemination has become possible with the recent development of a sperm separation technology called MicroSort, which relies on an identifiable difference between $\mathrm{X}$ and $\mathrm{Y}$ chromosome-bearing spermatozoa. $\mathrm{X}$ - and Y-bearing sperm cells differ in their total DNA content by $2.8 \%$, owing to the larger size of the $\mathrm{X}$ chromosome. A flow cytometric separation yields an average of $92 \%$ X-bearing and $73 \%$ Y-bearing sperm populations. ${ }^{7}$ The separated sperm populations can then be used for intrauterine insemination. Given that not every attempt of artificial insemination results in a pregnancy, couples will have to undergo an average of three to five cycles of insemination. Each attempt will cost about $\mathfrak{E} 1250$.

It can seem, therefore, that there is not yet any convenient method of sex selection. Sex-selective abortion requires the termination of a pregnancy; sex-selective embryo transfer necessitates in-vitro fertilization; and sexselective insemination is still ineffective. However, since it is likely that MicroSort will soon be refined, sex-selective insemination is certainly the technology of the future. As soon as this sperm separation technology develops into a safe and reliable procedure, sex selection may become attractive to many couples. The only thing that would be needed to have a child of the preferred sex would be a visit to a fertility clinic and several cycles of intrauterine insemination.

Scientific interest in the development of a sperm separation technique has mainly arisen from the desire to prevent X-linked disorders. There are more than 500 sex-linked diseases in humans, including haemophilia, Duchenne's muscular dystrophy, Lesch-Nyhan syndrome and Tay-Sachs disease. ${ }^{8}$ In most cases, the X-linked disorders are only expressed in the male offspring of carrier mothers. Thus, women who are carriers of a severe sex-linked disease often 
choose to have no children or to terminate their pregnancy if prenatal testing reveals the fetus to be a boy. A reliable sperm separation technology such as MicroSort would allow for the exclusive conception of unaffected girls.

Sex selection for the prevention of X-linked disorders is generally regarded as morally acceptable. The public debate, therefore, focuses almost entirely on sex selection for non-medical reasons. Many European countries, including Austria, Switzerland, Belgium, Italy and Germany, have passed legislation that makes sex selection for any but the most serious of medical reasons a crime. For instance, Germany's notorious Embryo Protection Act 1990 considers social sex selection a criminal offence punishable by one year of imprisonment. In the Australian state of Victoria, the sentence is even harsher. Under section 50 of the Infertility Treatment Act 1995 (Vic) doctors performing sex selection for non-medical reasons face up to two years of imprisonment in addition to ' 240 penalty units', which is equivalent to a fine of \$A24000. More recently, Canada enacted the Assisted Human Reproduction Act 2004 declaring that doctors performing sex selection for non-medical reasons are guilty of 'an offence and liable, on conviction on indictment, to a fine not exceeding \$CAN500 000 or to imprisonment for a term not exceeding ten years, or to both.'

Is there any valid justification for criminalizing social sex selection and for sentencing a doctor to jail for, say, helping the parents of three boys to finally conceive a girl? I don't think so - at least not in a Western liberal democracy.

Western societies are pluralistic societies. They consist of individuals with different concepts of the meaning of life, of the existence of God and of the ways to pursue happiness. Consequently, in modern societies there will always be irresolvable differences over what is the good for human beings. If a government tries to impose a particular morality upon its citizens, social conflict is inevitable. To avoid social tension and to deal with the moral pluralism of its citizens, Western societies ought to be based upon a 'presumption in favour of liberty': each citizen should have the right to live his or her life as he or she chooses so long as they do not infringe upon the rights of others. The state may interfere with the free choices of its citizens only to prevent harm to others.

This so-called 'harm principle', which has been developed by Wilhelm von Humboldt and John Stuart Mill, has three important implications. Firstly, the burden of proof is always on those who opt for a legal prohibition of a particular action. It is they who must show that the action in question is going to harm others. Secondly, the evidence for the harms to occur has to be clear and persuasive. It must not be based upon highly speculative sociological or psychological assumptions. And thirdly, the mere fact that an action may be seen by some as contrary to their moral or religious beliefs does not justify a legal prohibition. The domain of the law is not the enforcement of morality, but the prevention of harm to others. ${ }^{9}$ 
With this in mind, we shall turn to some of the most common objections to social sex selection and inquire whether they provide a rational basis for outlawing it.

A constantly recurring objection to sex selection is that choosing the sex of our children is to 'play God'. This religious objection has been made to all kinds of medical innovations. For example, using chloroform to relieve the pain of childbirth was once considered contrary to the will of God as it avoided the 'primeval curse on woman'. Similarly, the use of inoculations was opposed with sermons preaching that diseases are 'sent by Providence' for the punishment of sin and it is wrong of man to escape from such divine retribution. Since even fundamentalist Christians ceased to regard the alleviation of pain and the curing of diseases as morally impermissible, it is hard to take this objection seriously. What was once seen as 'playing God' is now seen as acceptable medical practice. More importantly, the objection that sex selection is a violation of 'God's Law' is an explicit religious claim. As Western liberal democracies are based on a strict separation of state and church, no government is entitled to pass a law to enforce compliance with a specific religion. People who consider the option of sex selection as contrary to their religious belief are free to refrain from it, but they are not permitted to use the coercive power of the law to impose their theology upon all those who do not share their religious world view. ${ }^{10}$

Some are opposed to sex selection because they have the feeling it is somehow 'unnatural'. Like the objection that choosing the sex of our children is playing God, the claim that sex selection is not natural most often expresses an intuitive reaction rather than a clearly reasoned moral response. That a particular human action is unnatural in no way implies that it is morally wrong. To transplant a heart to save a human life is certainly unnatural, but is it for that reason immoral? Surely not! Thus, if we have to decide whether an action is morally right or wrong we cannot settle the issue by asking whether it is natural or unnatural. ${ }^{11}$

A more serious objection to sex selection is based on the claim that medical procedures ought to be employed for medical purposes only. Flow cytometric sperm separation, it is argued, is a medical technology designed to enable couples who are at risk of transmitting a severe sex-linked genetic disorder to have a healthy child. In the absence of a known risk to transmit a serious $\mathrm{X}$-linked disease, there is simply no valid justification for employing flow cytometric sperm separation. This is a familiar objection in debates over novel applications of genetic and reproductive technologies. However, familiar as it may be, it is certainly not a persuasive one. We have already become accustomed to a healthcare system in which physicians provide services that have no direct medical benefit but that do have great personal value for the individuals seeking it. Given the acceptance of breast enlargements, hair replacements, ultrasoundassisted liposuctions and other forms of cosmetic surgery, one cannot, without 
calling that system into question, condemn a practice merely because it uses a medical procedure for lifestyle or child-rearing choices. ${ }^{12}$

A related objection is that offering a service for social sex selection constitutes an inappropriate use of limited medical resources. Again, if offering face-lifts is not considered to be a misallocation of scarce medical resources, it is hard to see how offering sex selection can be considered a misallocation of scarce medical resources. Moreover, by implying that every time a patient gets a nose-job another patient misses out on a bypass, this objection betrays a severely distorted conception of economics. If at all, this argument may apply to a state-run socialist economy based on a five-year plan, but certainly not to a private-run capitalist economy based on a free market. A chef opening a restaurant offering French cuisine does not deprive us of our daily bread. Similarly, a doctor opening up a fertility centre offering sex selection does not deprive us of basic health care. Provided their businesses are set up privately and their services are paid for privately, they don't deprive anyone of services.

Perhaps the most powerful objection to sex selection is that it may distort the natural sex ratio and lead to a socially disruptive imbalance of the sexes, as has occurred in countries such as India and China. ${ }^{13}$ However, it is an empirical question whether a distortion of the natural sex ratio poses a real threat to Western societies. It cannot be answered by intuition, but only by scientific evidence. For a severe sex ratio distortion to occur, at least two conditions must be met. Firstly, there must be a significant preference for children of a particular sex, and secondly there must be a considerable demand for a reproductive service for social sex selection. It is important to note that both conditions need to be met simultaneously. For example, if there was a marked preference for children of a particular sex, but couples were unwilling to use sex selection technology (because it was thought to be too intrusive, too expensive, immoral or simply against their religion), then a readily available service for sex selection would not have any demographic effect. Likewise, if there was considerable interest in employing sex selection technology, but couples did not have a marked preference for children of a particular sex (because they wish to have an equal number of boys and girls), then, again, a readily available service for preconception sex selection would not alter the sex ratio in any way. ${ }^{14}$

In order to ascertain whether the two preconditions for a sex ratio distortion are indeed met, we have conducted representative social surveys in Germany, the UK and the USA. In all three surveys, a randomized, computerassisted telephone interview tool was utilized to ask more than 1000 men and women between the age of 18 and 45 about their gender preferences and their interest in employing sex selection through sperm sorting. ${ }^{15}$

The first question asked was: 'If given a choice would you like your firstborn child to be a boy or a girl?' In Germany, 14\% of respondents preferred 
their first-born child to be a boy, $10 \%$ preferred it to be a girl, and a vast majority of $76 \%$ stated that they simply did not care about the sex of their first-born baby. The UK survey yielded a similar result: $16 \%$ of British men and women preferred their first-born child to be a boy, $10 \%$ a girl, and $74 \%$ said they did not care. In the USA, however, respondents had much stronger gender preferences for their first-born child: $39 \%$ preferred a boy, $19 \%$ preferred a girl, and only $42 \%$ did not mind the sex of their first child.

The second question was: 'If you were to have more than one child, would you prefer to have only boys, only girls, more boys than girls, more girls than boys, an equal number of boys and girls, or does the sex of your children not matter to you?' In Germany, $1 \%$ said they would like only boys, $1 \%$ only girls, $4 \%$ more boys than girls, $3 \%$ more girls than boys, $30 \%$ an equal number of boys and girls, and 58\% stated that they did not care. In the UK, 3\% wanted only boys, $2 \%$ only girls, $6 \%$ more boys than girls, $4 \%$ more girls than boys, an astonishing $68 \%$ an equal number of boys and girls, and $16 \%$ did not care about the sex of their offspring. In the USA, $5 \%$ stated they would like only boys, $4 \%$ only girls, $7 \%$ more boys than girls, $6 \%$ more girls than boys, $50 \%$ an equal number of boys and girls, and $27 \%$ said they did not mind their children's sex.

The third question inquired about the participants' interest in using MicroSort. In order to make an informed decision, they were told what this technology actually implies. Thus, they were informed that they would have to visit a fertility centre, to provide a sperm sample for flow cytometric separation, to undergo an average of three to five cycles of intrauterine insemination, and to pay a fee of approximately $\mathfrak{E} 1250$ per attempt. In Germany, 6\% could imagine taking advantage of MicroSort; however, an overwhelming majority of $92 \%$ found it simply to be out of the question. In the USA, the response was quite similar to that in Germany: only $8 \%$ could conceive of employing MicroSort, $18 \%$ were undecided, and $74 \%$ said they would not want to use it. Interestingly, in the UK, $21 \%$ were responsive to the idea of using MicroSort, $7 \%$ were undecided, and $71 \%$ said they cannot imagine taking advantage of it.

To establish whether the $92 \%$ of Germans and the $74 \%$ of Americans who rejected the idea of using MicroSort were in fact not interested in selecting the sex of their offspring or simply found the procedure to be too demanding, they were asked: 'Suppose the technology would require just a single cycle of artificial insemination, could be performed in any doctor's office and would be covered by your health insurance, would you then consider taking advantage of it?' Given these less demanding circumstances, $5 \%$ of Germans and 12\% of Americans were prepared to reconsider their unwillingness to use MicroSort, while $94 \%$ of Germans and $64 \%$ of Americans still rejected the idea of using it; $1 \%$ of Germans and $24 \%$ of Americans stated they were not sure. 
Finally, we asked the participants to imagine that there was a medication to select the sex of their children. Rather than visiting a fertility clinic, they would simply have to take a 'blue pill' to ensure the birth of a boy or a 'pink pill' to ensure the birth of a girl. While $8 \%$ of Germans and $18 \%$ of Americans were willing to use such a medication, $90 \%$ of Germans and $60 \%$ of Americans would not want to do so; $2 \%$ of Germans and 22\% of Americans were undecided. (Data from our UK survey have not yet been analysed.)

We are not sure why only $6 \%$ of Germans, $8 \%$ of Americans and $21 \%$ of Britons are interested in sex selection through sperm sorting. However, an additional German survey suggests a plausible answer. When we asked 1005 men and women about their moral attitudes towards sex selection and whether or not it should be made available to all couples requesting it, $86 \%$ of Germans were strongly opposed to it. In order to identify the concerns underlying the widespread enmity to social sex selection, participants were then asked about the reasons for their opposition. Eighty-seven per cent of respondents said that 'children are a gift and deserve to be loved for what they are, regardless of any characteristics such as beauty, intelligence or sex'; 79\% claimed that sex selection is 'playing God'; $76 \%$ were opposed because it was seen as 'unnatural'; $49 \%$ were afraid that it might skew the sex ratio; and $40 \%$ considered it to be 'sexist'. In light of this survey, it is safe to assume that the lack of interest in preconception sex selection is largely due to the fact that the overwhelming majority of Germans is strongly opposed to it. ${ }^{16}$

The same explanation might apply to the lack of interest in sex selection observed in the UK and the USA. According to a MORI opinion poll commissioned by the Human Fertilization and Embryology Authority, '69\% of Britains do not agree with the liberal proposition that any parent should have the right to choose the sex of their child. ${ }^{, 17}$ Similarly, according to a nationwide social survey commissioned by the Genetics \& Public Policy Center at the Johns Hopkins University, 'two thirds of Americans disapprove of sex selection for non-medical reasons'. ${ }^{18}$

Asking the proverbial 'man [or woman] on the Clapham omnibus' whether or not he would like to take advantage of MicroSort might not be the best way to determine the actual interest in using sex selection. After all, for most people it is a hypothetical question. Thus, we decided to survey pregnant women before having their first ultrasound. Do pregnant women (who usually spend some time wondering whether they are going to have a boy or a girl) have stronger gender preferences than the general public? Are they more interested in employing sex selection technology? And do their moral attitudes differ from the public at large?

In Germany, pregnant women do indeed differ from the general population. Firstly, they do have a significantly stronger preference for girls. While only $10 \%$ of the population at large wished their first-born child to be a girl, $18 \%$ of pregnant women hoped to have a baby girl first. Secondly, and quite 
surprisingly, they are even less interested in employing sex selection technology. Whereas $6 \%$ of the general population could imagine using MicroSort, only $3 \%$ of pregnant women could. And thirdly, their moral attitudes towards sex selection are much more 'liberal'. While $86 \%$ of the public at large were in favour of outlawing sex selection, only $57 \%$ of pregnant women were in support of a legal ban; $27 \%$ were undecided; and $16 \%$ were actually in favour of offering sex selection to all couples requesting it. ${ }^{19}$

A US survey conducted at Cleveland State University yielded a similar result. Of 140 women who were pregnant for their first time, $18 \%$ preferred to have a boy, $23 \%$ preferred to have a girl, and 59\% expressed no preference at all. Asked 'If the means were available to you so that you could have selected the sex of your child, would you have done so?', $18 \%$ answered with yes, $53 \%$ with no, and $29 \%$ were undecided. Of the 26 women who said they would have used sex selection, 13 would have done so to ensure the birth of a boy and 13 would have done so to ensure the birth of a girl. ${ }^{20}$

Finally, a UK survey conducted at the Centre for Family Research of the University of Cambridge produced a result akin to that of Germany and the USA. Of 2359 pregnant women who had been asked 'Do you mind what sex your baby is?', $6 \%$ preferred a boy, $6 \%$ preferred a girl, $12 \%$ quite liked a boy, $19 \%$ quite liked a girl, and $58 \%$ said they had no preference for a child of a particular sex. ${ }^{21}$

As we know all too well, there is often a yawning gap between what people say and what they actually do. Thus, it is reassuring that demographic research that has focused on examining when couples stop having more children does indeed confirm the stated preference for a so-called 'gender balanced family'. Couples with two boys and couples with two girls are more likely to have a third child than couples with one boy and one girl suggesting that parents with children of both sexes are more content with their family composition. This distinct trend towards a balanced family has not only been observed in Germany, the UK and the USA, but also in Canada, Italy, Spain, Sweden, Belgium, Austria, Switzerland and the Netherlands. $^{22}$

Maybe even more instructive than social surveys are data published by so-called 'gender clinics'. Worldwide, there are about 75 fertility centres that offer some method of sperm sorting followed by intrauterine insemination. According to The London Gender Clinic, within its first 18 months it had been consulted by only 809 couples. Of the 809 couples, 468 were of Indian origin, 259 European, 29 Chinese and the remaining 53 of other ethnic origins. The majority of European couples were seeking sex selection to 'balance their family', i.e. they already had two or three children of the same sex and wanted to have at least one child of the opposite sex: 'Our study shows that well over $95 \%$ of couples came for this sole purpose. They are predominantly men and women in their mid-30s nearing the end of their reproductive life and having 
on average 2-3 children of the same sex'. ${ }^{23}$ Similarly, the Gender Clinic of New York City reports that all of the 120 American couples seeking sex selection were doing so for family balancing purposes: 'They selected girls when they had boys at home and boys when there were only girls. ${ }^{24}$ Likewise, Gametrics Limited in Alzada, Montana, which detailed the collective experience of 65 gender clinics says: "The overwhelming majority had two or more children of the same sex and desired a child of the opposite sex. ${ }^{25}$ And finally, a report of the Genetics \& IVF Institute in Fairfax, Virginia, which is currently conducting a clinical trial on the safety and efficacy of MicroSort, states: 'The majority of couples $(90.5 \%)$ in our study were seeking gender preselection for family balancing purposes, were in their mid-thirties, had two or three children of the same sex, and desired only one more child. ${ }^{, 6}$

In conclusion, the widespread fear of a sex ratio distortion seems to be unjustified. The existing empirical evidence suggests that a readily available service for preconception sex selection will have only a negligible societal impact and is highly unlikely to cause a severe imbalance of the sexes in Western societies.

Although the threat of a sex ratio distortion is potentially the most troubling problem, it is also a problem that is most easily resolved - namely by limiting the service for sex selection to the purpose of 'family balancing'. If access to sex selection were restricted to parents having at least two children of the same sex, then helping them to have a child of the opposite sex would, if at all, only marginally alter the balance of the sexes. ${ }^{27}$

While a severe distortion of the natural sex ratio may not be a problem in Western countries, it surely is a problem in some Asian countries such as Pakistan, India, China and Korea. In India, thousands of girls are aborted, abandoned, neglected or even killed right after birth. The introduction of prenatal testing and selective abortion has apparently skewed the sex ratio of some regions of India to such an extent that there are now only 793 girls for every 1000 boys. According to a recent survey, 'prenatal sex determination and selective abortion accounts for half a million missing female births yearly. ${ }^{28}$ Given that the practice of sex-selective abortions has been common for most of the past two decades, it seems that about ten million female babies might have been aborted in India alone. In February 2003, the Indian parliament took action by amending its 'Preconception and Prenatal Diagnostic Techniques (Prohibition of Sex Selection) Act of 1994'. Doctors violating the Act now face a prison sentence of up to five years or a fine of 10000 to 50000 Rupees. Despite increased efforts to enforce the Act, however, the practice of sexselective abortions seems to be continuing. ${ }^{29}$

There are religious as well as economic reasons why Indians prefer boys over girls. According to Hinduism, a man who has failed to sire a son cannot achieve salvation. Only a male descendant can perform the last funeral rites to ensure the redemption of the departed soul. More importantly, Indian 
custom is that the parents of a girl are expected to pay a dowry for her marriage. The dowry payments are considerable. They extend from $£ 2500$ to $\mathfrak{E} 75000$. To marry off one or more daughters is therefore a huge financial burden. Since girls are a liability and boys are an asset, Indian couples have a strong incentive for seeking sex-selective abortions. Consequently, many medical practitioners offering ultrasound scans for sex determination have taken advantage of the excessive dowry demands when advertizing their services with the slogan 'Invest 500 Rupees now, save 500000 Rupees later!'30

Given the number of female abortions in India, it does not come as a surprise that some authors have called for a worldwide ban on social sex selection. ${ }^{31}$ However, does the practice of social sex selection in India really justify prohibiting social sex selection in countries such as Germany, the UK or the USA? The simple answer is: most certainly not! Firstly, preventing, say, British couples from choosing the sex of their children will not change the sex ratio of India. Secondly, even if it is only meant to 'send a message', it is simply naive to assume that Indian families will appreciate our gesture, well-meaning as it may be. As long as there are religious and economical incentives for preferring boys over girls, our moral plea will fall on deaf ears on the subcontinent. Thirdly, legalizing social sex selection in Great Britain does not jeopardize our right to criticize the practice of social sex selection in India. Approving of social sex selection through cytometric sperm separation or pre-implantation genetic diagnosis in no way implies that we approve of social sex selection through abortion or infanticide. Fourthly, and most importantly, denying British couples the opportunity to have a daughter because Indian couples have killed their girls would amount to punishing the innocent. There is no moral justification whatsoever for punishing the people of one country for actions committed by the people of another. $^{32}$

As we have seen, Western societies do not have to worry about an impending imbalance of the sexes. However, even if social sex selection may not distort the natural sex ratio, it may distort the natural birth order. Given that a substantial portion of the US population still prefers their first child to be a boy, it could be argued that sex selection technology may be abused to ensure the birth of a first-born 'son and heir'. Hence, another objection to social sex selection claims that we are at risk of 'creating a society of little sisters.' Once girls are second born, they will feel only second best. ${ }^{33}$ Is this a sound objection? I do not think so. Although it is, quite literally, 'conceivable', it is highly unlikely that hundreds of couples would employ sex selection technology for their first child to be a boy. As already pointed out, data from American and British 'gender clinics' suggest that the only couples willing to subject themselves to an intrusive and expensive treatment for preconception sex selection are couples who already have two or three children of the same sex and long to have at least one child of the opposite sex. According to a study 
by Nan P. Chico who analysed 2505 letters from couples inquiring about sex selection, 'only 1.4 per cent of these couples were seeking a first-born son, contrary to expectations based on an extensive review of the literature on gender preferences. ${ }^{34}$ Moreover, there is nothing in the literature on birth order studies that could possibly justify the claim that children who are second born feel second best. ${ }^{35}$

Another frequently advanced objection claims that sex selection is 'inherently sexist'. For example, the feminist philosopher Tabitha Powledge argues that, 'we should not choose the sexes of our children because to do so is one of the most stupendously sexist acts in which it is possible to engage. It is the original sexist sin.' Sex selection, she continues, is deeply wrong because it makes 'the most basic judgement about the worth of a human being rest first and foremost on its sex. ${ }^{36}$ However, this argument is deeply flawed. It is simply false that all people who would like to choose the sex of their children are motivated by the sexist belief that one sex is more valuable than the other. As we have seen, almost all couples seeking sex selection are simply motivated by the desire to have at least one child of each sex. If this desire is based on any beliefs at all, it is based on the quite defensible assumption that raising a girl is different from raising a boy, but certainly not on the preposterous idea that one sex is 'superior' to the other.

A further common objection concerns the welfare of children born as a result of sex selection. Thus, it has been argued that sex-selected children may be expected to behave in certain gender-specific ways and risk to be resented if they fail to do so. Although this cannot be completely ruled out, it is highly unlikely that children conceived after MicroSort are going to suffer from unreasonable parental expectations. Couples seeking sex selection to ensure the birth of a daughter are well aware that they can expect a girl, not some Angelina Jolie; and couples going for a son know perfectly well they can expect a boy, not some Brad Pitt.

Given that social sex selection is going to be a private reproductive service that needs to be paid out of pocket, some may worry about 'social injustice' arising from unequal access to technology. Hence it could be argued: 'Allowing wealthy couples to employ yet another highly expensive medical procedure would widen the gap between the rich and the poor beyond all bearing. No one should be allowed to use this technology unless all members of our society have access to it!' I do not wish to make fun of a serious ethical problem, but I cannot help being reminded of Woody Allen's famous joke in 'Annie Hall' where two old ladies are dining in an expensive restaurant in the Catskills: 'The food in this place is really terrible', says the first one. 'Yes', agrees the other, 'and such small portions!' The point is, I gather, sufficiently clear. If something is bad, we have no reason to complain that there is not enough of it. A complaint only makes sense if we are talking about some good. The same goes for sex selection. Opponents of social sex selection are 
undermining their own stance if they are criticizing the practice because it will inadvertently lead to inequality of access. If they are concerned about social justice they should not oppose sex selection, but promote it by claiming coverage through their public health insurance. As to the objection that nobody should use a new technology unless there is a guarantee that its benefits are equally shared by all members of society, this is, once again, a demand that ignores the economic facts of life. When first developed, automobiles, television sets and personal computers were so expensive only a minority could afford buying them. The only reason virtually all of us can now afford to buy a car, a TV or a PC is that we did not interfere with the creation of a market, stimulating competition and, consequently, lowering the prices. Thus, if we are really concerned about poor couples being 'left out', we should encourage, not discourage, couples to employ sex selection technology. This is potentially the best way to lower its current price.

Last but not least, there is the widely popular objection that sex selection is the first step down a road that will inevitably lead to the creation of 'designer babies'. Once we allow parents to choose the sex of their children, we will soon find ourselves allowing them to choose their eye colour, their height, or their intelligence. This slippery slope objection calls for three remarks. Firstly, it is not an argument against sex selection per se, but only against its alleged consequences. Secondly, and more importantly, it is based on the assumption that we are simply incapable of preventing the alleged consequences from happening. However, this view is utterly untenable. It is perfectly possible to draw a legal line permitting some forms of selection and prohibiting others. Thus, if selection for sex is morally acceptable but selection for, say, intelligence is not, the former can be allowed and the latter not. And thirdly, the slippery slope argument presumes that sliding down the slope is going to have detrimental, if not devastating, social effects. However, in the case of selecting offspring traits this is far from obvious. What is so terrifying about the idea that some parents may be foolish enough to spend their hard-earned money on genetic technologies just to ensure their child will be born with big brown eyes or black curly hair? I am sorry, but I cannot see that this would herald the end of civilization as we know it.

Since it cannot be established that preconception sex selection for nonmedical reasons would cause any harm to others, a legal ban is ethically unjustified. However, the fact that social sex selection ought not to be prohibited does not preclude regulating its practice. For example, it seems entirely appropriate to limit sex selection services to licensed centres subject to monitoring by health authorities. ${ }^{37}$ This would not only guarantee high scientific standards and high quality professional care, but it would also enable detailed research on possible demographic consequences and thus allow action if, contrary to expectations, significant imbalances were to develop. ${ }^{38}$ 


\section{NOTES AND REFERENCES}

1. D.S. Davis, Genetic Dilemmas: Reproductive Technology, Parental Choices, and Children's Futures (New York: Routledge, 2001).

2. G. Vines, 'The hidden cost of sex selection' (1993 May 1) 138(1871) New Scientist 12.

3. T. Powledge, 'Unnatural selection: on choosing children's sex' in: H. B. Holmes, B. B. Hoskins, M. Gross (eds.), The Custom-Made Child? Women-Centered Perspectives. (Totowa, New Jersey: Humana Press, 1981) 197.

4. J.J. Raymond, Women as Wombs. Reproductive Technology and the Battle Over Women's Freedom. (San Francisco: Harper, 1993).

5. L. de Crespigny, H.P. Robinson, A.C. Ngu, A. Robertson, J.L. Halliday, 'Transabdominal chorionic villus sampling: a safe and reliable procedure' (1991) 31(22) Australian \& New Zealand Journal of Obstetrics \& Gynaecology, 22-5.

6. A. Kuliev and Y. Verlinsky, 'Current features of Preimplantation genetic diagnosis' (2002) 5 Reproductive Biomedicine Online 294-9.

7. J.D. Schulman and D.S. Karabinus, 'Scientific aspects of preconception sex selection' (2005) 10 (Suppl. 1) Reproductive Biomedicine Online 111-15.

8. V. A. McKusick, Mendelian Inheritance in Man: A Catalog of Human Genes and Genetic Disorders, 12th edn (Baltimore: Johns Hopkins University Press, 1998).

9. H. L. A. Hart, Law, Liberty, and Morality. (Stanford, CA: Stanford University Press 1963); R. Taylor, Freedom, Anarchy, and the Law. (Totowa, New Jersey: PrenticeHall, 1973); T. C. Grey, The Legal Enforcement of Morality. (New York: Knopf, 1983); D. Lyons, Ethics and the Rule of Law. (Cambridge: Cambridge University Press, 1984); J. Feinberg, The Moral Limits of the Criminal Law. Volume One: Harm to Others. (New York: Oxford University Press, 1984); R. A. Epstein, Principles for a Free Society. Reconciling Individual Liberty with the Common Good. (Reading: Perseus, 1998).

10. Edgar Dahl, 'The presumption in favour of liberty. a comment on the HFEA's public consultation on sex selection' (2004) 8 Reproductive Biomedicine Online 266-7.

11. E. Dahl, 'Procreative liberty: the case for preconception sex selection' (2003) 7 Reproductive Biomedicine Online 380-4.

12. The Ethics Committee of the American Society for Reproductive Medicine, 'Preconception gender selection for nonmedical reasons' (2004) 82 (Suppl. 1) Fertility and Sterility 232-5.

13. A. Sen, 'Missing Women - Revisited' (2003) 327 British Medical Journal 1297-8.

14. E. Dahl, 'Preconception gender selection: a threat to the natural sex ratio' (2005) 10 (Suppl. 1) Reproductive Biomedicine Online 116-18.

15. E. Dahl, M. Beutel, B. Brosig, K.D. Hinsch, 'Preconception sex selection for non-medical reasons: a representative survey from Germany' (2003) 18 Human Reproduction 2231-4; E. Dahl, K. D. Hinsch, M. Beutel, B. Brosig 'Preconception sex selection for non-medical reasons: a representative survey from the United Kingdom' (2003) 18 Human Reproduction 2238-9; E. Dahl, R. S. Gupta, M. Beutel et al., 'Preconception sex selection: demand and preferences in the United States' (2006) 85 Fertility and Sterility 468-473. 
16. E. Dahl, K. D. Hinsch, B. Brosig, M. Beutel 'Attitudes towards preconception sex selection: a representative survey from Germany' (2004) 9 Reproductive Biomedicine Online 600-3.

17. Human Fertilisation and Embryology Authority, Sex Selection: Options for Regulation (London: Stationary Office, 2003).

18. Genetics \& Public Policy Center, Preimplantation Genetic Diagnosis: A Discussion of Challenges, Concerns, and Preliminary Policy Options Related to the Genetic Testing of Human Embryos. (Washington: Johns Hopkins University Press, 2004).

19. E. Dahl, B. Brosig, H.R. Tinneberg, S. Grüssner, 'Gender preferences and demand for sex selection: a survey among pregnant women in Germany' Human Reproduction (in press).

20. R. Steinbacher and F. D. Gilroy, 'Preference for sex of child among primiparous women' (1985) 119 The Journal of Psychology 141-7.

21. H. Statham, J. Green, C. Snowdon, M. France-Dawson, 'Choice of baby's sex' (1993) 341 Lancet 564-5.

22. C. Hank and H. P. Kohler, 'Gender preferences for children in europe: empirical results from 17 countries' (2000) 2 Demographic Research 1-21.

23. P. Liu and G. A. Rose, 'Social aspects of $>800$ couples coming forward for gender selection of their children' (1995) 10 Human Reproduction 968-71.

24. M. A. Khatamee, A. Leinberger-Sica, P. Matos, A. C. Weseley, 'Sex selection in New York City: who chooses which sex and why?' (1989) 34 International Journal of Fertility 353-4

25. F. J. Beermink, W. P. Dmowski, R. J. Ericsson, 'Sex preselection through albumin separation of sperm' (1993) 59 Fertility and Sterility 382-6.

26. E. F. Fugger, S. H. Black, K. Keyvanfar, J.D. Schulman 'Births of normal daughters after MicroSort sperm separation and intrauterine insemination, in-vitro fertilization, or intracytoplasmic sperm injection' (1998) 13 Human Reproduction 2367-70.

27. G. Pennings, 'Family balancing as a morally acceptable application of sex selection' (1996) 11 Human Reproduction 2339-45.

28. P. Jha, R. Kumar, P. Vasa et al., 'Low male-to-female sex ratio of children born in india: national survey of 1.1 million households' (2006) 367(9506) Lancet 211-18.

29. S. S. Sheth, 'Missing female births in India' (2006) 367(9506) Lancet 185-6.

30. Kusum, 'The use of Pre-Natal diagnostic techniques for sex selection: the indian scene' (1993) 7 Bioethics 149-65.

31. G. Benagiano and P. Bianchi, 'Sex preselection: an aid to couples or a threat to humanity?' (1999) 14 Human Reproduction 868-70; J. Quintavalle, Sex Selection: Choice and Responsibility in Human Reproduction. A Response of Comment on Reproductive Ethics (CORE) to the Human Fertilisation and Embryology Authority's (HFEA) Public Consultation on Sex Selection. (London: CORE, 2003); V. Hudson and A. Den Boer, Bare Branches: The Security Implications of Asia's Surplus Male Population. (Cambridge: MIT Press, 2004).

32. E. Dahl, 'No country is an island: a comment on the House of Commons' report Human Reproductive Technologies and the Law' (2005) 11 Reproductive Biomedicine Online 10-11. 
33. M. Darnowsky, 'Revisiting sex selection: the growing popularity of new sex selection methods revives an old debate' (2004) 17 GeneWatch 2-11.

34. N.P. Chico, Confronting the Dilemmas of Reproductive Choice: The Process of Sex Preselection, Accession Number AAG8926403, University of California, San Francisco, 1989.

35. Frank J. Sulloway, Born to Rebel: Birth Order, Family Dynamics, and Creative Lives (New York: Pantheon Books, 1996).

36. T. Powledge, 'Unnatural selection: on choosing children's sex' see note 3 above, 198.

37. J. Savulescu and E. Dahl, 'Sex selection and Preimplantation diagnosis: a response to the Ethics Committee of the American Society for Reproductive Medicine' (2000) 15 Human Reproduction 1879-80.

38. For further reading on the ethics of sex selection I recommend M. A. Warren, Gendercide: The Implications of Sex Selection (Towota, New Jersey: Rowman \& Allanheld, 1985); P. Singer and D. Wells, The Reproduction Revolution: New Ways of Making Babies. (New York: Oxford University Press, 1985); J. Savulescu, 'Sex selection: the case for' (1999) 171 Medical Journal of Australia 373-5; D. McCarthy, 'Why sex selection should be legal' (2001) 27 Journal of Medical Ethics 302-7; and J.A. Robertson, 'Preconception gender selection' (2001) 1 American Journal of Bioethics 2-9. 
